This article is licensed under the Creative Commons Attribution-NonCommercial 4.0 International License (CC BY-NC) (http://www.karger.com/Services/OpenAccessLicense). Usage and distribution for commercial purposes requires written permission.

\title{
Unilateral Posterior Polymorphous Corneal Dystrophy Presented as Anisometropic Astigmatism: 3 Case Reports
}

\author{
Hyun Sun Jeon ${ }^{\mathrm{a}}$ Joon Young Hyon ${ }^{\mathrm{a}, \mathrm{b}}$ \\ a Department of Ophthalmology, Seoul National University Bundang Hospital, \\ Seongnam, Republic of Korea; ${ }^{b}$ Department of Ophthalmology, Seoul National University \\ College of Medicine, Seoul, Republic of Korea
}

\section{Keywords}

Amblyopia · Anisometropia · Astigmatism · Corneal topography · Posterior polymorphous corneal dystrophy

\begin{abstract}
Background: Posterior polymorphous corneal dystrophy (PPCD) is typically considered bilateral and asymptomatic. However, few case reports on patients with unilateral PPCD with asymmetric refractive error have mentioned anisometropic amblyopia development. In support of this, we report 3 cases of unilateral PPCD that presented as anisometropic astigmatism. Visual prognosis related to amblyopia development is discussed. Case Presentation: All 3 patients had a band lesion in the affected eye and a difference of at least 1.5 diopters in cylindrical refractive error between their eyes. The affected eye had a greater amount of astigmatism in all cases. Two patients (Cases 1 and 2) also had amblyopia in the affected eye. Case 1 was a 25 -year-old male with a unilateral PPCD diagnosis and a band lesion involving the visual axis. Case 2 was an 11-year-old boy diagnosed with unilateral PPCD. The boy was treated with occlusion and atropine therapy over a 2-year period. Case 3 was a 4-year-old
\end{abstract}


girl diagnosed with unilateral PPCD. The girl had a 30-month history of corrective spectacle use and had no amblyopia. In all cases, the corneal endothelial cell count was lower in the affected eye than in the unaffected contralateral eye. Conclusions: Practitioners should closely monitor patients with unilateral PPCD for astigmatic anisometropia and amblyopia development. Visual prognosis for patients with unilateral PPCD may be related to lesion position, age at diagnosis, astigmatism severity, and early-childhood corrective spectacle use.

\section{Background}

Posterior polymorphous corneal dystrophy (PPCD) is a dominantly inherited disorder of the neural crest-derived corneal endothelium that is associated with characteristic corneal endothelial morphologic abnormalities $[1,2]$. The vast majority of patients have stable disease and are asymptomatic. However, in certain patients, corneal edema may develop as a result of endothelial dysfunction [3]. In general, PPCD is a bilateral disease but is asymmetric in some patients [3]. A few case reports on patients with unilateral PPCD with asymmetric refractive error have mentioned anisometropic amblyopia development [4, 5]. Here, we report 3 cases of unilateral PPCD that presented with astigmatic anisometropia. All patients had at least 1.5 diopter (D) cylindrical refractive error difference between their eyes. Clinical examination, corneal topography, corneal photography, and specular microscopy findings are presented. Visual prognoses are also discussed.

\section{Case Presentation}

The patient demographics and ocular examinations were summarized in Table 1.

Case 1

A 25-year-old male who planned to undergo corneal refractive surgery was referred to our corneal clinic due to suspected keratoconus because of astigmatism and decreased visual acuity in his left eye. He reported an interocular difference in visual acuity that began in childhood and claimed to have never had a decimal visual acuity in the left eye better than 0.8 . The patient denied a recent decrease in visual acuity and had no further medical or surgical history.

Uncorrected visual acuity (UCVA) was 0.2 in the right eye and 0.4 in the left eye. Bestcorrected visual acuity (BCVA) was 1.0 in the right eye and 0.8 in the left eye. Refractive error was -2.00 to $0.25 \times 165$ in the right eye and $+1.75-4.00 \times 10$ in the left eye. Slit-lamp examination revealed a horizontal band-like lesion at the level of Descemet's membrane and the corneal endothelium in the left eye (Fig. 1a). No remarkable corneal changes were observed in the right eye, and no other ocular abnormalities were observed in either eye. Noncontact specular microscopy (EM-4000; Tomey Ltd, Nagoya, Japan) revealed an endothelial cell density of 2,941 and 1,529 cells $/ \mathrm{mm}^{2}$ in the right and left eyes, respectively (Fig. 2a, b). Central corneal thickness was measured using contact corneal pachymetry (SP-3000; Tomey 
Ltd) and was $531 \mu \mathrm{m}$ in the right eye and $561 \mu \mathrm{m}$ in the left eye. Corneal topography (OPDScan III; Nidek Co. Ltd., Gamagori, Japan) of the left eye revealed a bow tie with-the-rule (WTR) astigmatism (steep $\mathrm{K}=43.55 \mathrm{D} \times 107$, flat $\mathrm{K}=41.46 \mathrm{D} 31$; ; Fig. 1b). The right eye had a mild WTR astigmatism (steep $\mathrm{K}=42.83 \mathrm{D} \times 93$, flat $\mathrm{K}=42.08 \mathrm{D} \times 3$; Fig. 1c). Interestingly, the corneal astigmatism flat cylinder axis corresponded to the band lesion axis in the left eye (affected eye; Fig. 1a, b). Anterior segment optical coherence tomography (Spectralis OCT; Heidelberg Engineering, Heidelberg, Germany) revealed an irregular, hyper-reflective posterior endothelial surface in the left eye (Fig. 3).

\section{Case 2}

An 11-year-old boy was referred to our corneal clinic for evaluation of astigmatism and possible amblyopia in the right eye. The patient had no history of ocular trauma, including forceps delivery. The boy had a 2-year history of corrective spectacle use and occlusion and atropine therapy in his left eye. Vision in his right eye did not improve after the 2 years of amblyopia therapy. At the time of presentation, UCVA was 0.2 in the right eye and 1.2 in the left eye, while BCVA was 0.7 in the right eye and 1.2 in the left eye. Refractive error was $+3.25-5.50 \times 15$ in the right eye and $+1.25-0.75 \times 5$ in the left eye. Slit-lamp examination revealed a snail-track lesion at the level of Descemet's membrane along the superotemporal cornea in the right eye (Fig. 1d). No remarkable corneal changes were observed in the left eye, and no other ocular abnormalities were observed in either eye. Noncontact specular microscopy revealed an endothelial cell density of 1,730 and 2,570 cells $/ \mathrm{mm}^{2}$ in the right and left eyes, respectively (Fig. 2c, d). Central corneal thickness was measured using noncontact corneal pachymetry (Spectralis OCT) and was $572 \mu \mathrm{m}$ in the right eye and $534 \mu \mathrm{m}$ in the left eye. Corneal topography (OPD-Scan III) of the right eye revealed an asymmetric bow tie WTR astigmatism with superior steepening (steep $\mathrm{K}=50.98 \mathrm{D} \times 95$, flat $\mathrm{K}=43.72 \mathrm{D} \times 5$; Fig. 1 e). The left eye had a mild WTR astigmatism (steep $\mathrm{K}=46.30 \mathrm{D} \times 93$, flat $\mathrm{K}=44.76 \mathrm{D} \times 3$; Fig. 1f).

\section{Case 3}

A 4-year-old girl was referred to our corneal clinic for evaluation of a corneal astigmatism and opacity. At the time of presentation, UCVA was 0.3 in the right eye and 0.2 in the left eye, while BCVA was 0.5 in both the right and left eyes. The refractive error was -0.75 to $1.25 \times 170$ in the right eye and $+0.50-2.75 \times 5$ in the left eye. Slit-lamp examination revealed a band-like lesion along the $40-50^{\circ}$ meridians at the level of Descemet's membrane in the left eye (Fig. 1g). No remarkable corneal changes were observed in the right eye, and no other ocular abnormalities were observed in either eye. Noncontact specular microscopy revealed an endothelial cell density of 3,322 and 1,845 cells $/ \mathrm{mm}^{2}$ in the right and left eyes, respectively (Fig. 2e, f). Central corneal thickness was measured using noncontact corneal pachymetry (Orbscan II; Bausch \& Lomb, Rochester, NY, USA) and was $566 \mu \mathrm{m}$ in the right eye and $564 \mu \mathrm{m}$ in the left eye. Corneal topography (Orbscan II) showed a bow tie WTR astigmatism (steep $\mathrm{K}=45.50 \mathrm{D} \times 95$, flat $\mathrm{K}=42.70 \mathrm{D} \times 5$; Fig. $1 \mathrm{~h}$ ) in the left eye and a more mild WTR astigmatism (steep $\mathrm{K}=44.70 \mathrm{D} \times 90$, flat $\mathrm{K}=43.10 \mathrm{D} \times 180$; Fig. $1 \mathrm{i}$ ) in the right eye. After 30 months of spectacle correction, the patient's vision improved to 0.9 in the right eye and 0.8 in the left eye. Corneal topography did not change in either eye over this 30 month period. 


\section{Case Reports in Ophthalmology}

Case Rep Ophthalmol 2017;8:250-258

(C) 2017 The Author(s). Published by S. Karger AG, Base www.karger.com/cop

Jeon and Hyon: Unilateral Posterior Polymorphous Corneal Dystrophy Presented as Anisometropic Astigmatism: 3 Case Reports

\section{Conclusions}

The 3 patients described in this case series had unilateral PPCD accompanied by an interocular cylindrical refractive error difference $\geq 1.5 \mathrm{D}$. In each case, the eye with PPCD had the greater astigmatism, strongly suggesting a relationship between the corneal lesion and astigmatism. This observation is in agreement with prior studies [5, 6]. Briefly, DeRespinis et al. [6] reported that a greater amount of astigmatism was found in the eyes with a greater amount of PPCD in their pediatric cases [6]. Case 1 in the current report had a flat cylinder axis that corresponded to the corneal band lesion axis. Although it could be an incidental coincident case, the eyes affected by PPCD had a more severe WTR nature of the astigmatism compared to the unaffected eyes in all 3 patients, suggesting that endothelial lesions may be associated with developing astigmatism.

Al-Amry and Khan [5] recently reported a case of unilateral PPCD with ipsilateral anisometropic amblyopia. Their findings suggest that children with PPCD are at risk for visual loss from refractive amblyopia even when corneas are clear, particularly children with asymmetric disease. Among the 3 patients described here, only 2 (Cases 1 and 2) had amblyopia. The third case (Case 3) occurred in a 4-year-old girl who had been using corrective spectacles over a 30-month period. Our PPCD cases with amblyopia was noted in older patients since amblyopia obviously developed at a younger age before they had visited a hospital; a 25-year-old male with a band lesion that involved the pupil and an 11-year-old boy who was unresponsive to occlusion and atropine therapy following a 2-year treatment period. Therefore, it is possible that early detection of PPCD and use of corrective spectacles during the amblyogenic period (approximately 0-8 years) may have improved the patient's prognosis in Case 3. In support of this, the United States Preventive Services Task Force (2004) recommends vision screening for children younger than 5 years [7]. Based on the observations made in this case series, we suggest the possible visual prognosis of patients with unilateral PPCD in the aspect of amblyopia development. In cases of unilateral PPCD, patients may develop an asymmetric refractive error and have a greater astigmatism in the affected eye. The position of the lesion, the age at diagnosis, astigmatism severity, and corrective spectacle use in early childhood may influence visual prognosis of unilateral PPCD.

As other studies reported, PPCD is associated with a lower endothelial cell count $[8,9]$; endothelial cell densities were lower in the eye with PPCD than in the contralateral eye in all 3 of our patients. Longitudinal comparison studies that evaluate endothelial cell density and corneal thickness in patients with unilateral PPCD would be helpful in determining how endothelial pump function is affected.

Recent studies have shown that some families with PPCD have steep corneal curvatures ( $>46.0 \mathrm{D}$ ) that are not related to keratoconus [10], and some of these families carry the zinc finger E-box binding homeobox 1 (ZEB1) gene mutation [11, 12]. Of our 3 cases, only 1 patient (Case 2) had abnormally steep corneal curvature values $(>46.0 \mathrm{D})$ in both eyes $(50.98 \mathrm{D}$ in the affected eye and $46.30 \mathrm{D}$ in the unaffected eye). Corneal curvature values in the affected eye of the remaining 2 patients were $43.55 \mathrm{D}$ in Case 1 and $45.50 \mathrm{D}$ in Case 3. Unfortunately, analysis of the ZEB1 gene was not performed in our patients, so we were unable to examine the relationship between the $Z E B 1$ genotype and corneal curvature. Further studies that examine the ZEB1, COL8A2, and VSX1 genes in patients with unilateral PPCD would be helpful to better understand the role of these genes in PPCD pathogenesis. Although it is 
possible that the contralateral eye of the patients presented here could eventually develop PPCD, all 3 patients showed a unilateral lesion, suggesting that factors other than genotype can affect PPCD pathogenesis. This would be supported by the fact that, to the best of our knowledge, there has not been a single case presenting solely with snail tracks molecularly confirmed to have PPCD.

In conclusion, patients with unilateral PPCD may have astigmatic anisometropia, which may be an amblyogenic factor. Children with anisometropia or asymmetric astigmatism should be carefully examined by a corneal specialist to have the anterior and posterior corneal surfaces thoroughly evaluated via slit-lamp examination. Corneal topography may also be helpful in determining astigmatism severity and irregularity. Additionally, PPCD patients, particularly those with unilateral disease, should be closely followed, and practitioners should monitor these patients for amblyopia development. These precautions should also be followed in early-onset cases. Early intervention with corrective lenses could prevent anisometropic amblyopia in the affected eye.

\section{Statement of Ethics}

This study was approved by the Institutional Review Board of Seoul National University Bundang Hospital (IRB No. B-1607-354-702). The study complied with the guidelines of the Declaration of Helsinki.

\section{Disclosure Statement}

The authors have no conflicts of interest to disclose.

\section{Author Contribution}

H.S.J. was the major contributor in writing the manuscript. H.S.J. and J.Y.H. designed and made a concept of the study, interpreted the patient data, and gave final approval of the manuscript to be published.

\section{References}

-1 Shimizu S, Krafchak C, Fuse N, Epstein MP, Schteingart MT, Sugar A, Eibschitz-Tsimhoni M, Downs CA Rozsa F, Trager EH, Reed DM, Boehnke M, Moroi SE, Richards JE: A locus for posterior polymorphous corneal dystrophy (PPCD3) maps to chromosome 10. Am J Med Genet 2004;130a:372-377.

2 Jang MS, Roldan AN, Frausto RF, Aldave AJ: Posterior polymorphous corneal dystrophy 3 is associated with agenesis and hypoplasia of the corpus callosum. Vision Res 2014;100:88-92.

3 Weisenthal RW, Streeten BW: Descemet's membrane and endothelial dystrophies; in Krachmer JH, Mannis MJ, Holland EJ (eds): Cornea, ed 3. Saint Louis, Mosby/Elsevier, 2011, pp 845-864.

4 Bozkurt B, Ozkan F, Yilmaz M, Okudan S: Posterior corneal steepening in posterior polymorphous corneal dystrophy. Optom Vis Sci 2015;92:e414-e419. 
Al-Amry M, Khan AO: Unilateral posterior polymorphous corneal dystrophy associated with ipsilateral anisometropic amblyopia. J Pediatr Ophthalmol Strabismus 2013;50:e55-e57.

-6 DeRespinis PA, Norden RA, Rispoli LC: Posterior polymorphous dystrophy associated with astigmatism and amblyopia in children. J Refract Surg 1996;12:709-714.

-7 U.S. Preventive Services Task Force: Screening for visual impairment in children younger than age 5 years: recommendation statement. Ann Fam Med 2004;2:263-266.

-8 Liskova P, Palos M, Hardcastle AJ, Vincent AL: Further genetic and clinical insights of posterior polymorphous corneal dystrophy 3. JAMA Ophthalmol 2013;131:1296-1303.

-9 Liskova P, Filipec M, Merjava S, Jirsova K, Tuft SJ: Variable ocular phenotypes of posterior polymorphous corneal dystrophy caused by mutations in the ZEV1 gene. Ophthalmic Genet 2010;31:230-234.

10 Raber IM, Fintelmann R, Chhabra S, Ribeiro MP, Eagle RC, Orlin SE: Posterior polymorphous dystrophy associated with nonkeratoconic steep corneal curvatures. Cornea 2011;30:1120-1124.

-11 Evans CJ, Liskova P, Dudakova L, Hrabcikova P, Horinek A, Jirsova K, Filipec M, Hardcastle AJ, Tuft SJ: Identification of six novel mutations in ZEB1 and description of the associated phenotypes in patients with posterior polymorphous corneal dystrophy 3. Ann Human Genet 2015;79:1-9.

$\checkmark 12$ Aldave AJ, Ann LB, Frausto RF, Nguyen CK, Yu F, Raber IM: Classification of posterior polymorphous corneal dystrophy as a corneal ectatic disorder following confirmation of associated significant corneal steepening. JAMA Ophthalmol 2013;131:1583-1590. 


\section{Case Reports in Ophthalmology}

Case Rep Ophthalmol 2017;8:250-258

(C) 2017 The Author(s). Published by S. Karger AG, Basel www.karger.com/cop

Jeon and Hyon: Unilateral Posterior Polymorphous Corneal Dystrophy Presented as Anisometropic Astigmatism: 3 Case Reports
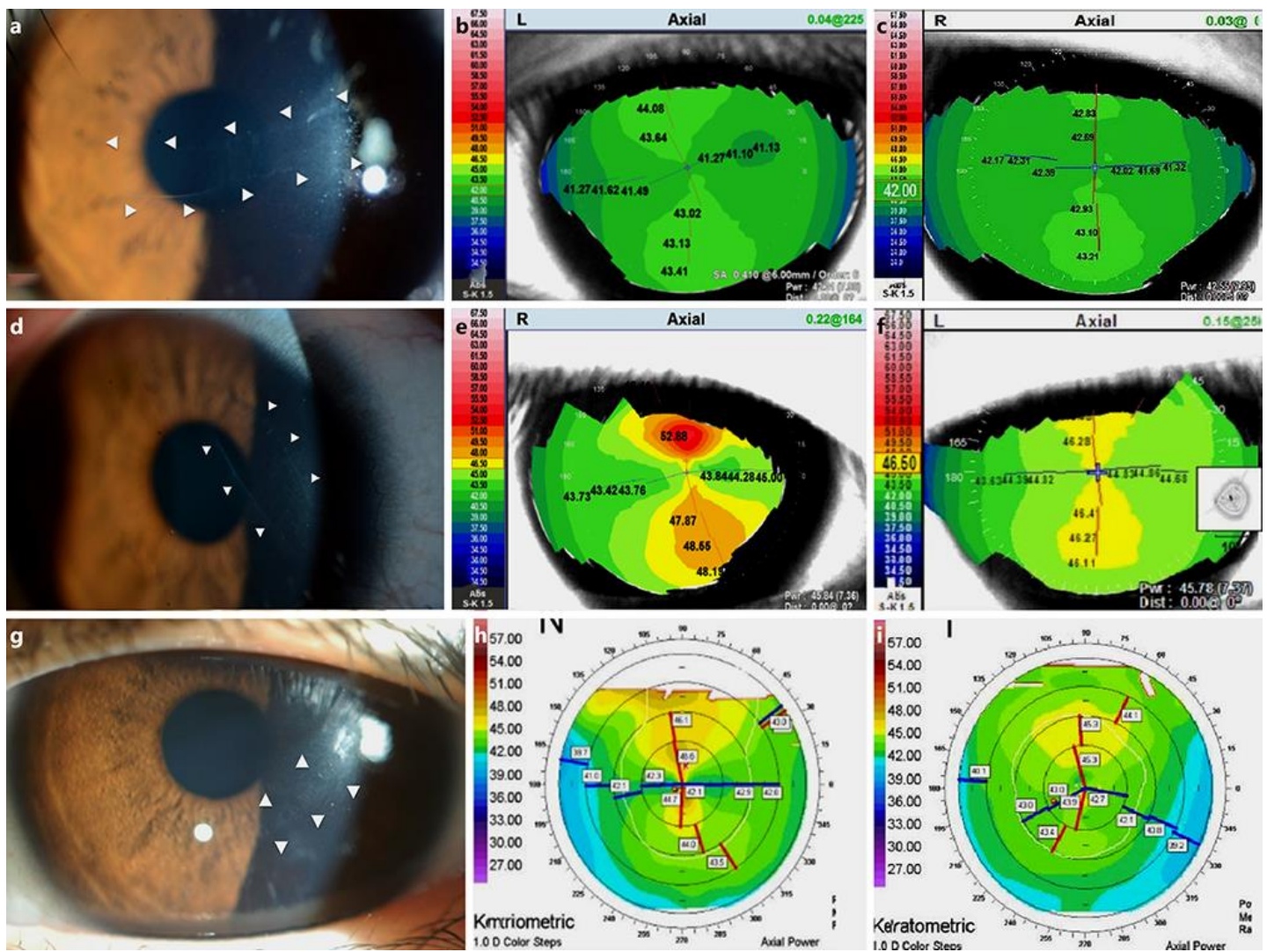

Fig. 1. Anterior segment photography and corneal topography of 3 patients with unilateral posterior polymorphous corneal dystrophy. a Anterior segment photography of a 25-year-old male (Case 1). The left eye showed a horizontal band-like lesion at the level of Descemet's membrane and the corneal endothelium (arrowheads). b Corneal topography of case 1 revealed a bow tie, with-the-rule (WTR) astigmatism (steep $\mathrm{K}=43.55 \mathrm{D} \times 107$, flat $\mathrm{K}=41.46 \mathrm{D} \times 17$ ). Interestingly, the corneal astigmatism flat cylinder axis corresponded to the band lesion axis. $\mathrm{c}$ Corneal topography of the uninvolved eye of case 1 showed a mild WTR astigmatism (steep $\mathrm{K}=42.83 \mathrm{D} \times 93$, flat $\mathrm{K}=42.08 \mathrm{D} \times 3$ ). $\mathrm{d}$ Anterior segment photography of an 11-yearold boy (Case 2). The left eye showed a snail-track lesion at the level of Descemet's membrane along the superotemporal cornea (arrowheads). e Corneal topography of case 2 showed an asymmetric bow tie WTR astigmatism with superior steepening (steep $\mathrm{K}=50.98 \mathrm{D} \times 95$, flat $\mathrm{K}=43.72 \mathrm{D} \times 5$ ). $\mathrm{f}$ Corneal topography of the uninvolved eye of case 2 showed a mild WTR astigmatism (steep K= 46.30 D $\times 93$, flat $\mathrm{K}=44.76 \times 3$ ). g Anterior segment photography of a 4-year-old girl (Case 3). It showed a band-like lesion along the 40-50 meridians at the level of Descemet's membrane (arrowheads). $\mathbf{h}$ Corneal topography of case 3 revealed a bow tie WTR astigmatism (steep $\mathrm{K}=45.5 \mathrm{D} \times 95$, flat $\mathrm{K}=42.7 \mathrm{D} \times 5$ ). $\mathbf{i}$ Corneal topography of the uninvolved eye of case 3 showed a mild WTR astigmatism (steep $\mathrm{K}=44.7 \mathrm{D} \times 90$, flat $\mathrm{K}=43.1 \mathrm{D} \times 180$ ). 


\section{Case Reports in Ophthalmology}
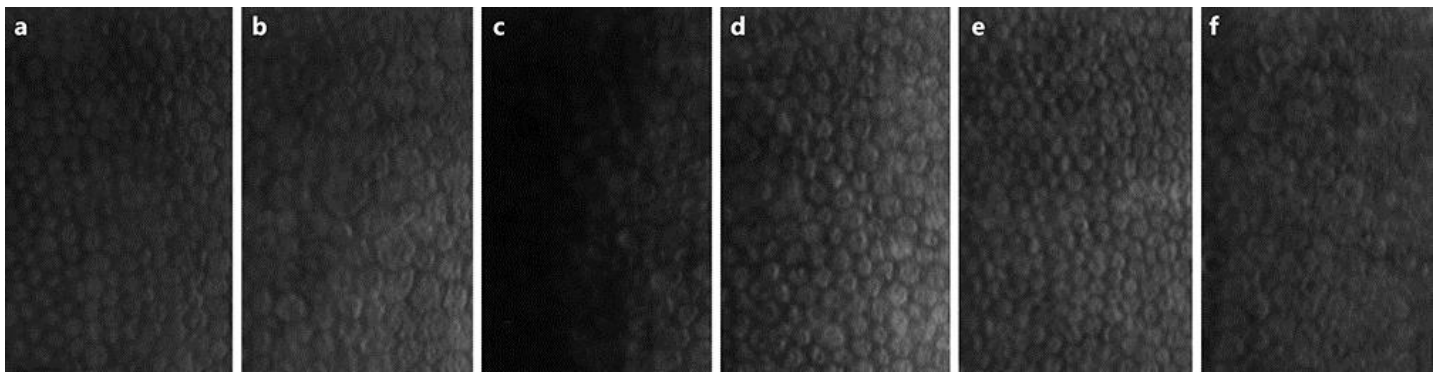

Fig. 2. Specular microscopy images of patients with unilateral posterior polymorphous corneal dystrophy (PPCD). a, b A 25-year-old male with PPCD in his left eye (Case 1). In the right eye (a), no abnormalities were seen, and the endothelial cell count was 2,941 cells $/ \mathrm{mm}^{2}$. In the left eye (b), variations in cell size and morphology were observed, and the endothelial cell count was 1,529 cells $/ \mathrm{mm}^{2}$. c, d An 11-year-old boy with PPCD in his right eye (Case 2). In the right eye (c), variations in cell size and morphology were observed and the endothelial cell count was $1,730 \mathrm{cells} / \mathrm{mm}^{2}$. In the left eye (d), no abnormalities were observed, and the endothelial cell count was 2,570 cells $/ \mathrm{mm}^{2}$. e, f A 4-year-old girl with PPCD in her left eye (Case 3). In the right eye (e), no abnormalities were seen, and endothelial cell count was 3,322 cells $/ \mathrm{mm}^{2}$. In the left eye (f), variations in cell size and morphology were seen, and the endothelial cell count was 1,845 cells $/ \mathrm{mm}^{2}$.

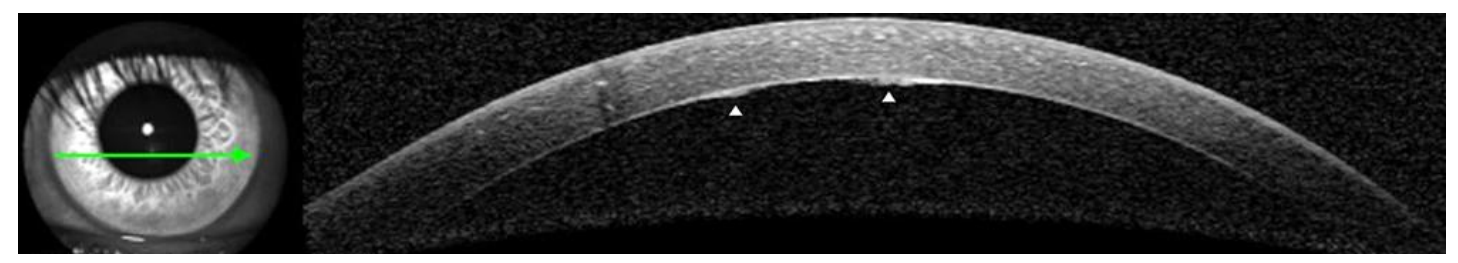

Fig. 3. Anterior segment optical coherence tomography of a patient (Case 1). It showed irregular posterior endothelial surface with hyperreflectivity in his left eye. 


\section{Case Reports in Ophthalmology}

Jeon and Hyon: Unilateral Posterior Polymorphous Corneal Dystrophy Presented as Anisometropic Astigmatism: 3 Case Reports

Table 1. Summary of patient demographics and ocular examinations

\begin{tabular}{|c|c|c|c|}
\hline & $\begin{array}{l}\text { Case } 1 \\
(25 \text { years })\end{array}$ & $\begin{array}{l}\text { Case } 2 \\
\left(11 \text { years }^{a}\right)\end{array}$ & $\begin{array}{l}\text { Case } 3 \\
\left(4 \text { years }^{\mathrm{a}}\right)\end{array}$ \\
\hline Sex & Male & Male & Female \\
\hline Laterality & Left & Right & Left \\
\hline BCVA (right/left) & $1.0 / 0.8$ & $0.7 / 1.2$ & $0.9 / 0.8$ \\
\hline \multicolumn{4}{|c|}{ Refractive error (spherical [D]/cylinder[D]/axis $\left[{ }^{\circ}\right]$ ) } \\
\hline Right & $-2.00 /-0.25 / 165$ & $+3.25 /-5.50 / 15$ & $-0.75 /-1.25 / 170$ \\
\hline Left & $+1.75 /-4.00 / 10$ & $+1.25 /-0.75 / 5$ & $+0.50 /-2.75 / 5$ \\
\hline \multicolumn{4}{|c|}{ Endothelial cell density, cells $/ \mathrm{mm}^{2}$} \\
\hline Right & 2,941 & 1,730 & 3,322 \\
\hline Left & 1,529 & 2,570 & 1,845 \\
\hline \multicolumn{4}{|c|}{ Keratometry (steep K/flat K) } \\
\hline Right & $42.83 / 42.08$ & $50.98 / 43.72$ & $44.70 / 43.10$ \\
\hline Left & $43.55 / 41.46$ & $46.30 / 44.76$ & $45.50 / 42.70$ \\
\hline \multicolumn{4}{|c|}{ Central corneal thickness, $\mu \mathrm{m}$} \\
\hline Right & 531 & 572 & 566 \\
\hline Left & 561 & 534 & 564 \\
\hline
\end{tabular}

BCVA, best-corrected visual acuity; D, diopter. a Age at presentation. 